\title{
Kuchenbecker J (ed) Plates for Color Vision Testing
}

\author{
(2013), ISBN: 978-3-131-75481-3 Thieme
}

Lyle Gray

Received: 2 July 2014 / Accepted: 8 July 2014 / Published online: 24 July 2014

(C) Springer-Verlag Berlin Heidelberg 2014

This book is the first English-language version of a color vision test originally developed by Jakob Stilling over 100 years ago. The book is in truth mainly a test with a little explanatory text and instructions for use.

The book contains a useful introductory section regarding the physiological basis of color vision processing and the types of color vision deficiency that can be found in the population. There is also a section regarding the use of the plates themselves to test color vision and the steps to be undertaken where diagnosis is unclear.

The test itself is similar to the format of the Ishihara test with a series of numbers, letters, and an "illiterate E" format presented mostly as vanishing optotypes, where the patient with a color vision deficiency will fail to see any symbols, although two plates have a transformation format where the symbols appear differently to those with color vision deficiency. Unlike the Ishihara test, which can detect only red-green color vision deficiency, this test has three plates, which can detect blue-yellow deficiencies also.

We used the test in our color vision clinic at the university and found it to be very comparable to other screening tests such as the Ishihara, Farnsworth D-15, and the City Test, and we felt it was very useful to have a simple plate test which incorporated screening plates for both red-green and blueyellow color vision deficiencies.

Clearly, this test can only be regarded as a screening test for identifying the presence of a color vision deficiency and the authors are clear on this point in their instructions. If there is any doubt over the diagnosis or a more detailed assessment of the severity of the color vision anomaly is required, then more advanced testing with anomaloscopy or the FarnsworthMunsell 100 Hue test may be required. However, as a screening test, this book would make a useful addition to the bookshelf of any optometrist or ophthalmologist.
L. Gray $(\bowtie)$

Department of Life Sciences, School of Health and Life Sciences, Glasgow Caledonian University, Cowcaddens Road, Glasgow G4 0BA, UK

e-mail: L.S.Gray@gcal.ac.uk 